\title{
Can "Complex" Market Designs Make it from Theory to Practice? Changing the Course Allocation Mechanism at Wharton
}

\author{
Eric Budish \\ The University of Chicago Booth School of Business \\ 5807 South Woodlawn Avenue \\ Chicago, IL 60637 \\ +1 773 702-8453 \\ Eric.Budish@chicagobooth.edu
}

\begin{abstract}
Budish (2011) proposes a new mechanism for the problem of combinatorial assignment -- e.g., assigning students to schedules of courses -- called approximate competitive equilibrium from equal incomes (CEEI). While the CEEI mechanism satisfies attractive properties of efficiency, fairness, and incentives, it is "complicated" in several ways that one might reasonably wonder whether the theory could actually be implemented in the real world. To give just a few examples, agents are assumed to report their complete preferences over all possible schedules of courses, the mechanism is assumed to solve a high-dimensional approximate Kakutani fixed point problem, and all of the economic properties the mechanism satisfies involve approximations. While there is no perfect definition of a mechanism's complexity, for a contrast consider the famous GaleShapley deferred acceptance algorithm, which is sufficiently simple to imagine implementing in practice that the medical profession actually did so some fifteen years before Gale and Shapley's paper was even published.

This talk reports on two papers (Budish and Kessler, 2015; Budish et al., 2015) that helped bring this complex market design theory to successful implementation in practice, at the Wharton School at the University of Pennsylvania. The first paper, joint with Judd Kessler, reports on experiments conducted at Wharton to test the CEEI mechanism. In addition to showing that the CEEI mechanism improved the efficiency and fairness of the allocation, the experiment also serves as a roadmap for other market design researchers seeking to test complex mechanisms in practice. The second paper, joint with Gerard Cachon, Judd Kessler, and Abe Othman, reports on the computational and economic engineering work involved in actually implementing the
\end{abstract}

mechanism in practice. This involved modifications of the CEEI mechanism to deal with some of the issues caused by approximations in the theory, and a computational procedure that performs a massive parallel heuristic search, solving billions of mixed-integer programs along the way, to output an approximate competitive equilibrium in the fake-money economy for courses.

\section{Categories and Subject Descriptors}

J.4 [Social and Behavioral Sciences]: Economics

\section{General Terms}

Economics; Algorithms; Design

\section{Keywords}

Market design, matching, combinatorial allocation, course allocation, scheduling, Tabu search, competitive equilibrium, experiments, preference elicitation, user interface design.

\section{REFERENCES}

[1] Budish, E.B. 2011. The Combinatorial Assignment Problem: Approximate Competitive Equilibrium from Equal Incomes. J. Polit. Econ. 119, 6 (Dec. 2011), 1061-1103. DOI= http://www.jstor.org/stable/10.1086/664613.

[2] Budish, E.B. and Judd Kessler, 2015. Can "Complex" Market Designs Make it from Theory to Practice? An Experiment that Changed the Course Allocation Mechanism at Wharton. Working Paper.

[3] Budish, E.B.; G.P. Cachon; J. Kessler; and A. Othman, 2015. Course Match: A Large-Scale Implementation of Approximate Competitive Equilibrium from Equal Incomes for Combinatorial Allocation. Working Paper. 